\title{
A Safe and Ensured Prevention of Osteoporosis in Women After Menopause
}

\section{Kimihiko Okazaki}

Okazaki Medical Clinic, Ukyoku, Kyoto, Japan

Corresponding author: Kimihiko Okazaki, Okazaki Medical Clinic, Ukyoku, Kyoto, Japan, Tel: 207-277-2020; E-mail: ma13081x@ma1.seikyou.ne.jp

Rec Date: March 24, 2017, Acc Date: April 13, 2017, Pub Date: April 15, 2017

Citation: Okazaki K. A Safe and Ensured Prevention of Osteoporosis in Women After Menopause. Med Case Rep, 3: 2.

\section{Perspective}

It is well known that the rate of absorption of calcium from bones into blood plasma increases after menopause due to the accompanied decrease in the rate of endogenous secretion of estrogen from ovaries. It is also well known that excessive exogenous supply of estrogen augments the risk-rate of carcinogenesis.

On the other hand, it appears that little is known about a safe and ensured method of prevention of carcinogenesis. As a matter of fact, discovery of a specific cancer drug has been reported as long as 32 years ago [1]. Although the discoverer did not demonstrate the mechanism of action of the stuff, it is highly possible that the stuff inhibits activity of tyrosine kinase, which is the rate-limitting enzyme in the pass-way of carcinogenesis [2]. The basis of this argument is an enzymologically established concept that a chemical compound, of which structure is similar to that of the substrate of the enzyme, exhibits an inhibitory activity towards the enzyme. To be more convincing, the enzyme molecule accepts the inhibitor into its substrate site as an error. Both of tyrosine and benzaldehyde have benzene nucleus and carbonate radical in common.

In conclusion, per OS intake of both of estrogen and benzoate is the safe and ensured prevention of osteoporosis in women after menopause. In more detail, $0.625 \mathrm{mg}$ of estrogen (Premarin; Pfizer) and $250 \mathrm{mg}$ of Benfothiamine every 5 days will do the job. As far as the reason why the discovery of the specific cancer drug has not been known widely is concerned, I can't tell anything since I'm not an oncologist.

\section{References}

1. Kochi M (1985) Antitumor activity of a benzaldehyde derivative. Cancer Treatment Reports 69: 533-537.

2. Okada M, Nakagawa $H$ (1989) A protein tyrosine kinase involved in regulation of pp60 function. J Biol Chem 264: 20886-20893. 